\title{
HUBUNGAN SCORING DENTAL ANXIETY SCALE DENGAN PERUBAHAN TEKANAN DARAH PASIEN EKSTRAKSI GIGI DI PUSKESMAS BAHU
}

\author{
${ }^{1}$ Frisly Tamunu \\ ${ }^{2}$ Frans E. Wantania \\ ${ }^{3}$ Ni Wayan Mariati
}

\author{
${ }^{1}$ Kandidat Skripsi Program Studi Pendidikan Dokter Gigi Fakultas Kedokteran \\ ${ }^{2}$ Bagian Penyakit Dalam Fakultas Kedokteran \\ ${ }^{3}$ Program Studi Pendidikan Dokter Gigi Fakultas Kedokteran \\ Universitas Sam Ratulangi Manado \\ Email: iintamunu@gmail.com
}

\begin{abstract}
Anxiety is a feeling experienced by individuals when thinking that something unpleasant will happen. This study aimed to determine the relationship between dental anxiety scoring scale and changes in blood pressure. This was a descriptive analytical study with a cross sectional design conducted in health center Bahu. Population was all patients with tooth extraction performed on them. Samples were chosen by using purposive sampling method. Data were obtained by using questionnaire of dental anxiety scale and blood pressure measured in the waiting room and on the dental chair before tooth extraction. Data were analyzed statistically by using univariate and bivariate analyses with Spearman test. The results showed that before tooth extraction, there were patients with anxiety as well as patients with increased blood pressure. The age group 21-30 years and females were the majority that experienced anxiety. The correlation between DAS and changes in systolic blood pressure showed a $\mathrm{P}$ value of 0.066 and in diastolic blood pressure a $P$ value of 0.705 . Conclusion: There was no relationship between dental anxiety scoring scale and blood pressure changes among patients with tooth extraction in Public Health Center Bahu.
\end{abstract}

Keywords: scoring dental anxiety scale, blood pressure, tooth extraction

\begin{abstract}
Abstrak: Kecemasan adalah perasaan yang dialami oleh individu ketika berpikir bahwa sesuatu yang tidak menyenangkan akan terjadi.. Penelitian ini bertujuan untuk mengetahui hubungan skoring dental anxiety scale (DAS) dengan perubahan tekanan darah. Penelitian ini menggunakan metode deskriptif analitik dengan pendekatan potong lintang yang dilakukan di puskesmas Bahu. Populasi dan sampel ialah seluruh pasien yang berkunjung di Puskesmas Bahu yang melakukan tindakan ekstraksi gigi sesuai dengan kriteria inkslusi. Teknik pengambilan sampel menggunakan purposive sampling. Data diambil menggunakan kuesioner DAS dan pengukuran tekanan darah dilakukan saat menunggu dan saat berada di kursi dental sebelum tindakan ekstraksi gigi. Data diolah dengan menggunakan analisis univariat dan bivariat mengunakan uji Spearman. Hasil penelitian menunjukkan, pada tindakan ekstraksi gigi terdapat pasien yang mengalami kecemasan dan terdapat pasien yang mengalami peningkatan tekanan darah. Usia 21-30 tahun merupakan usia terbanyak yang mengalami kecemasan serta jenis kelamin perempuan paling banyak merasa cemas. Hubungan antara DAS dan perubahan tekanan darah sistol dari hasil uji statistik diperoleh nilai $\mathrm{p}=0,066$ dan diastol $p=0,705$. Simpulan: Tidak terdapat hubungan antara DAS dan perubahan tekanan darah pasien ekstraksi gigi di Puskesmas Bahu.
\end{abstract}

Kata kunci: DAS, tekanan darah, ekstraksi gigi 
Pada umumnya masyarakat awam memberi kesan bahwa praktek dokter gigi memiliki suasana dan peralatan yang asing, dan terlebih lagi berhubungan dengan rasa nyeri. Hal ini menyebabkan pasien menjadi cemas sehingga mempengaruhi kunjungan rutin pasien untuk berobat ke dokter gigi. Kecemasan dalam praktek dokter gigi merupakan halangan yang sering mempengaruhi perilaku pasien dalam perawatan gigi. ${ }^{1}$

Kecemasan adalah perasaan yang dialami oleh individu ketika berpikir bahwa sesuatu yang tidak menyenangkan akan terjadi. Gejala fisiologis yang menyertai kecemasan adalah perangsangan susunan saraf simpatis dan peningkatan sekresi hormon adrenalin seperti berkeringat banyak, ketegangan otot, tekanan darah yang meningkat, jantung berdebar-debar, sulit makan, susah tidur, sesak nafas, mudah tersinggung dan nyeri daerah ulu hati. $^{2}$

Pasien yang menunggu perawatan untuk mencabut gigi pada umumnya cemas, karena pasien sudah memikirkan komplikasi yang akan terjadi jika gigi pasien di cabut. Perdarahan adalah salah satu komlikasi yang paling ditakuti oleh pasien karna dianggap dapat mengancam kehidupan. $^{3}$

Kecemasan dental ini paling sering diukur menggunakan kuesioner. Kuesioner yang akan digunakan dalam penelitian ini yaitu Corach dental anxiety scale (DAS), merupakan skala yang menunjukkan 4 reaksi berbeda dalam situasi atau prosedur yang temukan di klinik gigi, yaitu: 1) sebelum datang ke tempat praktik dokter gigi; 2) saat menunggu perawatan; 3) saat duduk di dental unit; dan 4) saat menjalani perawatan. $^{4}$

Berdasarkan hasil penelitian yang telah dilakukan di rumah sakit gigi dan mulut pendidikan $\mathrm{Hj}$. Halimah Dg. Sikati Makassar yang juga menggunakan alat ukur Corach DAS, ditemukan bahwa responden yang mengalami tingkat kecemasan sedang, tinggi, dan sangat cemas berjumlah 27 orang (54\%) dari total
50 subjek yang di teliti responden. Hal ini menandakan bahwa separuh pasien yang akan melakukan pencabutan gigi mengalami kecemasan. ${ }^{5}$

Kecemasan pre-operative memiliki sifat subjektif, dan secara sadar perasaan tentang kecemasan serta ketegangan yang disertai perangsangan sistem saraf otonom menyebabkan peningkatan tekanan darah dan denyut jantung. Hal ini sangat berbahaya karena tingginya denyut jantung dan tekanan darah memperberat sistem kardiovaskuler dan meningkatkan kebutuhan akan oksigen dan kerja jantung. Selain itu, kecemasan yang dialami oleh pasien akan semakin meningkat apabila adanya persepsi dari pasien, yaitu keterampilan atau keahlian dokter gigi yang akan melakukan prosedur pencabutan gigi tersebut masih cukup kurang. ${ }^{1}$

Dari hasil observasi di Puskesmas Bahu, Poli gigi dan mulut di Puskesmas Bahu memiliki pasien rata-rata 5-10 orang per hari; 2 diantaranya merupakan pasien yang datang merupakan pasien yang datang untuk mencabut gigi. Penelitian ini bertujuan untuk mengetahui hubungan antara kecemasan dental pasien menggunakan alat ukur Corach DAS dan perubahan tekanan darah pasien ekstraksi gigi di Puskesmas Bahu.

\section{METODE PENELITIAN}

Penelitian ini merupakan penelitian deskriptif analitik dengan rancangan potong lintang. Penelitian ini dilaksanakan pada bulan Febuari- Agustus 2015.

Jumlah sampel yang diteliti sebanyak 31 orang dengan teknik pengambilan sampel menggunak purposive sampling. Pasien diberikan kuesioner untuk dijawab dan diukur tingkat kecemasan berdasarkan DAS. Selanjutnya dilakukan pengukuran tekanan darah yang diulangi saat berada di dental unit sebelum dilakukan tindakan ekstraksi gigi. Data diolah dan disajikan berdasarkan distribusi frekuensi dalam bentuk tabel dengan menggunakan uji Spearman. 


\section{HASIL PENELITIAN}

Tabel 1. Distribusi frekuensi berdasarkan tingkat kecemasan sebelum dilakukan ekstraksi gigi

\begin{tabular}{ccc}
\hline Tingkat & $\mathrm{n}$ & $\%$ \\
Kecemasan & & \\
\hline Tidak cemas & 19 & 62 \\
Sedang & 6 & 19 \\
Tinggi & 0 & 0 \\
Sangat cemas & 6 & 19 \\
Total & 31 & 100 \\
\hline
\end{tabular}

Tabel 2. Distribusi frekuensi berdasarkan perubahan tekanan darah saat menunggu dan saat berada di kursi dental

\begin{tabular}{ccc}
\hline $\begin{array}{c}\text { Perubahan } \\
\text { tekanan darah }\end{array}$ & $\mathrm{n}$ & $\%$ \\
\hline Tetap & 24 & 77 \\
Naik & 5 & 17 \\
Turun & 2 & 6 \\
Total & 31 & 100 \\
\hline
\end{tabular}

Tabel 3. Distribusi frekuensi kecemasan berdasarkan kelompok usia

\begin{tabular}{ccccccccc}
\hline $\begin{array}{c}\text { Usia } \\
\text { (tahun) }\end{array}$ & \multicolumn{9}{c}{ Tingkat Kecemasan } \\
\cline { 2 - 9 } & \multicolumn{1}{l}{$\begin{array}{l}\text { Tidak } \\
\text { cemas }\end{array}$} & \multicolumn{3}{c}{ Sedang } & Tinggi & \multicolumn{3}{l}{$\begin{array}{l}\text { Sangat } \\
\text { cemas }\end{array}$} \\
& $\mathrm{n}$ & $\%$ & $\mathrm{n}$ & $\%$ & $\mathrm{~N}$ & $\%$ & $\mathrm{n}$ & $\%$ \\
\hline $17-20$ & 0 & 0 & 1 & 3,2 & 0 & 0 & 1 & 3,2 \\
$21-30$ & 6 & 19,4 & 2 & 6,5 & 0 & 0 & 2 & 6,5 \\
$31-40$ & 4 & 12,9 & 1 & 3,2 & 0 & 0 & 0 & 0 \\
$41-50$ & 6 & 19,4 & 2 & 6,5 & 0 & 0 & 1 & 3,2 \\
$51-60$ & 2 & 6,5 & 0 & 0 & 0 & 0 & 2 & 6,5 \\
$61-70$ & 1 & 3,2 & 0 & 0 & 0 & 0 & 0 & 0 \\
\hline
\end{tabular}

\section{BAHASAN}

Emosi, kecemasan, rasa takut, stres fisik dan rasa sakit dapat meningkatkan tekanan darah oleh karena stimulasi sistem saraf simpatis meningkatkan curah jantung dan vasokonstriksi arteriol sehingga meningkatkan hasil tekanan darah.

Hasil distribusi frekuensi berdasarkan tingkat kecemasan sebelum dilakukan ekstraksi gigi diperoleh pasien yang mengalami kecemasan sedang berjumlah 6 orang $(19,4 \%)$ dan sangat cemas berjumlah
Tabel 4. Distribusi frekuensi berdasarkan jenis kelamin

\begin{tabular}{ccccc}
\hline Tingkat & \multicolumn{2}{c}{ Laki-Laki } & \multicolumn{2}{c}{ Perempuan } \\
\cline { 2 - 5 } Kecemasan & $\mathrm{N}$ & $\%$ & $\mathrm{n}$ & $\%$ \\
\hline Tidak cemas & 11 & 35,5 & 8 & 25,8 \\
Sedang & 1 & 3,2 & 5 & 16,1 \\
Tinggi & 0 & 0 & 0 & 0 \\
Sangat & 0 & 0 & 6 & 19,4 \\
cemas & & & & \\
\hline
\end{tabular}

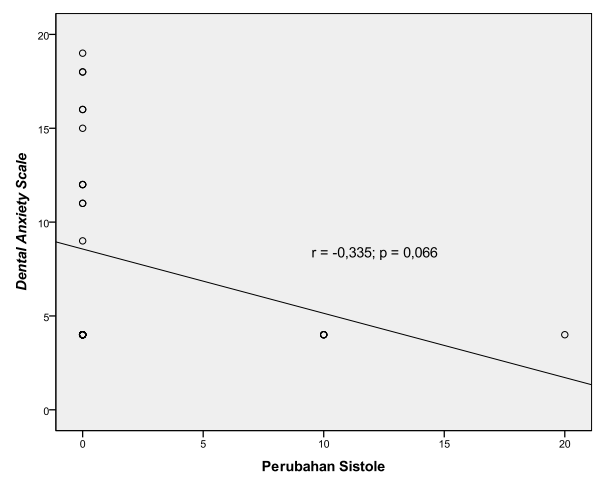

Gambar 1. Kurva Korelasi antara DAS dan Perubahan Tekanan Darah Sistol

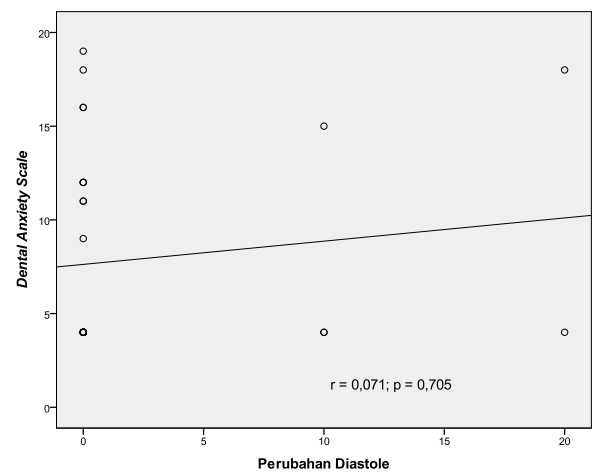

Gambar 2. Kurva Hubungan antara DAS dan Perubahan Darah Diastol

6 orang (19,4\%). Tingkat kecemasan sedang dan sangat cemas termasuk dalam kategori cemas meskipun tingkat kecemasannya berbeda-beda. Jadi dapat disimpulkan bahwa responden yang merasa cemas pada kategori ini sebanyak 12 orang (38,7\%). Hasil dari penelitian ini sesuai dengan penelitian sebelumnya yang menunjukkan bahwa dalam tindakan ekstraksi gigi terdapat pasien yang mengalami kecemasan sedang, tinggi dan sangat cemas. $^{4}$ 
Tamunu, Wantania, Mariati: Hubungan scoring dental...

Hasil distribusi frekuensi berdasarkan perubahan tekanan darah saat menunggu dan saat berada di kursi dental menunjukkan pasien yang mengalami peningkatan tekanan darah berjumlah 5 orang $(16,1 \%)$, yang mengalami penurunan tekanan darah berjumlah 2 orang (6,5\%) dan yang tidak mengalami perubahan tekanan darah berjumlah 24 orang $(77,4 \%)$. Tekanan darah yang meningkat dan menurun dikategorikan sebagai tekanan darah yang mengalami perubahan yaitu berjumlah 7 orang (22,6\%). Hal ini sangat berhubungan dengan tingkat kecemasan yang dialami oleh pasien sebelum dilakukan pencabutan gigi. Kecemasan, emosi, rasa takut, stres fisik, dan rasa sakit dapat meningkatkan tekanan darah oleh karena stimulasi sistem saraf simpatis meningkatkan curah jantung dan vasokonstriksi arteriol, sehingga tekanan darah meningkat. Pada keadaan stres atau cemas, medula kelenjar adrenal akan menyekresikan norepinefrin dan epinefrin yang keduanya akan menyebabkan vasokonstriksi sehingga meningkatkan tekanan darah. ${ }^{7}$

Penelitian DAS dari hasil distribusi frekuensi kecemasan berdasarkan kelompok usia, didapatkan pasien yang mengalami kecemasan terbanyak berada di usia 21-30 tahun berjumlah 4 orang (12,9\%) dan yang kedua terbanyak berada pada kelompok usia 41-50 tahun dengan jumlah 3 orang $(9,7 \%)$. Hasil penelitian ini hampir sama dengan hasil penelitian oleh Kumar dkk yang menjelaskan bahwa tingkat kecemasan dental yang paling tinggi berada pada usia 25-34 tahun. ${ }^{8}$

Keadaan cemas pada ekstraksi gigi bisa dialami oleh siapa saja. Hasil distribusi frekuensi kecemasan berdasarkan jenis kelamin menunjukkan perempuan lebih banyak mengalami kecemasan untuk melakukan ekstraksi gigi. Hal ini dikarenakan jumlah pasien perempuan lebih dominan dibandingkan laki-laki yang relatif sedikit. Dari 31 pasien ekstraksi gigi, laki-laki yang mengalami kecemasan berjumlah 1 orang $(3,2 \%)$ dan perempuan berjumlah 11 orang (35,5\%). Penelitian ini sesuai dengan penelitian para ahli di Australia yang mengatakan perempuan lebih banyak mengalami kecemasan dibandingkan laki-laki karena perempuan memiliki ambang nyeri yang lebih rendah dan lebih mudah dipengaruhi oleh tekanan lingkungan. ${ }^{9}$

Gambar 1 menunjukkan hubungan antara DAS dengan perubahan tekanan darah. Dari hasil uji statistik didapatkan korelasi negatif lemah $(\mathrm{r}=0,335)$ yang tidak signifikan ( $>00,05 ; \quad p=0,066)$ antara perubahan sistole dan DAS. Pada Gambar 2 didapatkan korelasi positif sangat lemah $(r=0,071)$ yang tidak signifikan ( $>0,05$; $\mathrm{p}=0,705)$ antara perubahan diastol dan DAS.

Terdapat beberapa kemungkinan mengapa penelitian ini tidak menunjukkan hubungan yang signifikan. Pertama, hampir semua pasien yang diteliti tidak mengalami kecemasan. Kedua, jumlah pasien yang diteliti hanya 31 orang sehingga terdapat keterbatasan dalam menentukan hubungan antara tingkat DAS dan perubahan tekanan darah.

\section{SIMPULAN}

Berdasarkan hasil penelitian dapat disimpulkan bahwa tidak terdapat hubungan antara DAS dan tekanan darah sistol dan diastol.

\section{SARAN}

1. Dokter gigi harus mampu memahami cara mengatasi kecemasan agar dalam penanganannya dokter gigi dapat menenangkan pasien yang merasa cemas menjadi tidak cemas karena masih banyak dokter gigi yang hanya terfokus pada faktor fisik dan tidak memperhatikan faktor psikis pasien.

2. Perlu dilakukan sosialisasi kepada masyarakat tentang kesehatan gigi dan mulut agar masyarakat yang cenderung takut ke dokter gigi tidak akan takut lagi untuk memeriksakan giginya ke dokter gigi ataupun mendapat perawatan dari dokter gigi. 


\section{DAFTAR PUSTAKA}

1. Prasetyo EP. Peran musik sebagai fasilitas dalam praktek dokter gigi untuk mengurangi kecemasan pasien. Maj Ked Gigi (Dent J). 2005;38 (1):41-4.

2. Bolla IN. Gambaran Tingkat Kecemasan Pada Klien Pra Bedah Mayor Di Ruang Rawat Inap Medikal Bedah Gedung D Lantai 3 Rumah Sakit Umum Cibabat Cimahi. [online] 2009. Available from: http://www.stikesayani.ac.id/publikas i/ejournal/files/2009/200908/200908005.pdf

3. PSMKGI. Penanganan Perdarahan Pasca Ekstraksi Gigi. 2007. Available from: http://www.penanganan-perdarahanpasca-eksraksi-gigi.htm. Accessed: 14 Oct 2010.

4. Joel F. Measure for clinical practice. New York, 1994.

5. Permatasari R. Hubungan kecemasan dental dengan perubahan tekanan darah pasien ekstraksi gigi di rumah sakit gigi dan mulut pendidikan $\mathrm{Hj}$. Halimah Makassar [skripsi]. 2013

6. Widyaningsih NN, Latifah M. Pengaruh keadaan sosial ekonomi, gaya hidup, status gizi, dan tingkat stress terhadap tekanan darah. Jurnal Gizi dan Pangan. 2008;3(1):1-6.

7. Berman A, Snyder S, Kozier B, Erb G. Buku ajar praktik keperawatan klinis Kozier dan Erb. 5th ed. Jakarta: EGC, 2009; p. 41-2

8. Kumar S, Bhargav P, Patel A, Bhati M, Balasubramanyam G, Duraiswamy P, et al. Does dental anxiety influences oral health-related quality of life ? Observation from a crosssectional study among adults in Udaipur district, India. Journal of Oral Science. 2009;51(2):245-54.

9. Hmud R, Walsh LJ. Dental Anxiety Causes, Complication and Management Approaches. J Minim Interv Dent. 2009;2(1):70. 